\title{
Retardation of 4-Hydroxy-2-Transnonenal (HNE), a Toxic Aldehyde Formation by Antioxidants in Heat-Treated Corn Oil at Frying Temperature
}

\author{
Wei Jin, D. W. Shoeman, Vijai K. S. Shukla, A. Saari Csallany* \\ Department of Food Science and Nutrition, University of Minnesota, Saint Paul, USA \\ Email: *ascsalla@umn.edu
}

How to cite this paper: Jin, W., Shoeman, D.W., Shukla, V.K.S. and Csallany, A.S. (2020) Retardation of 4-Hydroxy-2-Transnonenal (HNE), a Toxic Aldehyde Formation by Antioxidants in Heat-Treated Corn Oil at Frying Temperature. Food and Nutrition Sciences, 11, 669-683.

https://doi.org/10.4236/fns.2020.117048

Received: May 24, 2020

Accepted: July 11, 2020

Published: July 14, 2020

Copyright $\odot 2020$ by author(s) and Scientific Research Publishing Inc. This work is licensed under the Creative Commons Attribution International License (CC BY 4.0).

http://creativecommons.org/licenses/by/4.0/

\section{Open Access}

\begin{abstract}
The antioxidative properties of four antioxidants such as rosemary extracts (RE), tert-butylhydroquinone (TBHQ), ascorbyl palmitate (AP), citric acid (CA) and their mixtures were investigated on the formation of 4-hydroxy-2transnonenal (HNE) in commercial corn oil heated at $185^{\circ} \mathrm{C}$ for up to 6 hours. Among the antioxidants $100 \mathrm{ppm} \mathrm{RE}$ and a mixture of $200 \mathrm{ppm}$ tertiary butylated hydroquinone (TBHQ) $+100 \mathrm{ppm}$ ascorbyl palmitate (AP) + $50 \mathrm{ppm}$ citric acid (CA) exhibited excellent antioxidative activity, as determined by the thiobarbituric acid reaction (TBARS) assay, measuring the formations of the secondary lipid oxidation products and by high-performance liquid chromatography (HPLC), measuring the formation of the toxic $\alpha$, $\beta$-unsaturated hydroxyaldehyde HNE after heat treatment of corn oil at $185^{\circ} \mathrm{C}$ up to 6 hours. TBHQ, AP and CA alone did not show much protective properties. The synergistic effects of TBHQ + AP + CA mixture shown to reduce the formation of HNE after 6 hours heat-treated corn oil by $27 \%$. RE $100 \mathrm{ppm}$ was also found to be a very effective antioxidant, reducing the formation of HNE after 6 hours heat-treated corn oil in the same condition by $29 \%$.
\end{abstract}

\section{Keywords}

Antioxidants, Ascorbyl Palmitate, Citric Acid, Corn Oil, HNE, Rosemary Extracts, TBHQ

\section{Introduction}

Lipid peroxidation of polyunsaturated fatty acids (PUFA) leads to a large variety 
of secondary lipid peroxidation products, including the $\alpha, \beta$-unsaturated hydroxyaldehydes such as the toxic aldehyde 4-hydroxy-2-transnonenal (HNE) [1] [2] [3]. This polar very reactive aldehyde containing unsaturation between the $\alpha$ and $\beta$ carbons and has a hydroxyl group on the carbon 4 position. The chemical structure makes this aldehyde very reactive to amino, sulfhydryl and thiol groups and therefore reacts aggressively with biological compounds. Among the four $\alpha, \beta$-unsaturated hydroxyaldehydes (HHE, HOE, HNE, HDE), the 9 carbon containing HNE was found to be the most reactive and toxic compound [4]-[12]. Its toxicity has been demonstrated in the literature by its reaction to DNA and RNA in low concentrations and related to a number of pathological conditions including inflammatory and degenerative processes such as atherosclerosis, liver damage, Parkinson's, Alzheimer's and other diseases [13]-[19].

It has been shown that the precursor of HNE is linoleic acid [20] and corn oil together with soybean oil contain high levels of this fatty acid. Corn oil contains about $60 \%$ linoleic acid and is commonly used for frying in the food industry, frying fast foods commercially and used also in households for frying. A number of previous experiments have shown the formation of HNE due to heat treatments in the above oils by this laboratory [20]-[25]. It is known that certain antioxidants can delay the reactions of lipid peroxidation and therefore could cause some protection to heat-treated PUFA oils, and lower the formation of secondary lipid oxidation products. HNE, a toxic secondary lipid oxidation product, was shown to form linoleic acid due to heat treatment at frying temperatures and it has also been shown to incorporate into fried food [26] [27]. Since HNE has been shown to be absorbed from the diet and metabolized [28], it is important to investigate how its formation can be reduced during heat treatments at frying temperature. The objective of the present study was to measure the antioxidant effects of several synthetic and a naturally occurring antioxidant, rosemary [29] and measure the lowering effects of the formation of the most toxic and abundant $\alpha, \beta$-unsaturated hydroxyaldehyde isomer, HNE in heat-treated corn oil which is high in linoleic acid, a precursor for HNE.

\section{Materials and Methods}

\subsection{Chemicals and Instruments}

Mazola corn oil was purchased from a local store (Roseville, MN). The 2,4-dinitrophenylhydazine was obtained from Eastman Kodak Company. (Rochester, NY). The HPLC-grade methanol, HPLC-grade water, HPLC-grade dichloromethane, trichloroacetic acid, boron trifluoride-methanol solution and TBHQ were all from Sigma Chemical Company (St. Louis, MO). Rosemary extract (RE), Fortium R30 containing 4\% of carnosoic acid and carnosol mixture in sunflower oil. It was obtained from Kemin Industries Inc. (Des Moines, IA). Sodium thiosulfate, and glacial acetic acid were purchased from Fisher Scientific (Fair Lawn, NJ). Hydrochloric acid and potassium iodide were obtained from Mallinckrodt Baker Inc. (Paris, KY). HPLC-grade hexane was obtained from EMD Chemicals, 
Inc. (Gibbstown, NJ). Citric acid and L-ascorbyl palmitate were purchased from MC/B Manufacturing Chemists (Norwood, OH) and MP Biomedicals, LLC (Solon, $\mathrm{OH}$ ) respectively. No. 1 filter paper and $0.45 \mu \mathrm{m}$ syringe filters were obtained from Whatman Ltd. (Kent, England). Thin layer chromatographic (TLC) plates were purchased from EMD Millipore, Inc. (Billerica, MA). HNE was purchased from Cayman Chemical Company (Ann Arbor, MI).

The fatty acid distribution was measured on a gas chromatograph containing an 18835B capillary inlet system (5830A Gas Chromatograph, Hewlett-Packard, Saginaw, MI).

Thiobarbituric acid (TBA) reactivity was measured using a UV/vis Bausch and Lomb Spectronic 20 spectrophotometer at $535 \mathrm{~nm}$.

The high-performance liquid chromatograph (HPLC) system contained a sample injector (712 WISP, Waters, Milford MA, USA), a solvent delivery system (9050, Varian, Walnut Creek, CA) and a UV-Vis detector (9010, Varian). The HPLC column was an Ultrasphere ODS $5 \times 4.6 \mathrm{~mm}, 25 \mathrm{~cm}$ column (Hichrom, Berkshire, UK) with a guard column (Deerfield, IL).

\subsection{Methods}

The detailed methods used in the present experiments was described by Seppanen and Csallany [21] [22] and recently by Juan, Shoeman and Csallany [25].

\section{Stock Solutions in $10 \mathrm{~mL}$ Ethanol:}

1) 5 mg Rosemary extract (RE);

2) $10 \mathrm{mg}$ Rosemary extract (RE);

3) $20 \mathrm{mg}$ Tertiary Butylhydroquinone (TBHQ);

4) $20 \mathrm{mgTBHQ}+5 \mathrm{mg}$ Citric acid (CA);

5) $20 \mathrm{mg} \mathrm{TBHQ}+10 \mathrm{mg}$ Ascorbyl palmitate (AP);

6) $20 \mathrm{mg} \mathrm{TBHQ}+5 \mathrm{mg} \mathrm{CA}+10 \mathrm{mg} \mathrm{AP}$;

7) Control; $10 \mathrm{~mL}$ Ethanol.

\section{Sample Preparations}

The $0.5 \mathrm{~mL}$ stock solutions of antioxidants were added to $5 \mathrm{~mL}$ of corn oil samples to produce the following $\mathrm{mg} / \mathrm{L}$ (ppm) concentrations: a) RE 50 and 100 ppm, b) TBHQ 200 ppm, c) TBHQ 200 ppm + CA 50 ppm, d) TBHQ 200 ppm + AP 100 ppm, e) TBHQ 200 ppm + CA 50 ppm + AP 100 ppm, f) Control only ethanol, no antioxidants.

\section{Heating Conditions of Commercial Corn Oil Samples}

Duplicate samples of $5 \mathrm{~g}$ commercial corn oil and $0.5 \mathrm{~mL}$ of the various stock solutions in ethanol were mixed using a shaker for $5 \mathrm{~min}$ before heating. All samples were heated in the center of the preheated $185^{\circ} \mathrm{C}$ sand bath in a $5 \mathrm{~cm} \times$ $15 \mathrm{~cm}$ open glass tube. The test tubes were inserted $10 \mathrm{~cm}$ down into the sand bath. The temperature of the oil was monitored and in about $20 \mathrm{~min}$ the oil reached to $185^{\circ} \mathrm{C}$ in the test tube and then held for the entire heating time of 1 or 2 or 4 or 6 hours. The duplicate samples were heated together for each time period and removed from the sand bath at the same time. The samples, after heat 
treatments, were cooled and used for analysis immediately. From each duplicate samples, two $1 \mathrm{~mL}$ samples (a total of 4 samples) used for the TBARS assays. For the HPLC analysis of HNE, the oil samples were heated again as before in duplicates, for 1 or 2 or 4 or 6 hours at $185^{\circ} \mathrm{C}$ separately and used for the analyses. The unheated samples were ( 0 heating time) used as references for measuring the start of the thermally induced oxidation process of the commercial corn oil. The stock solution No. 7, contained no antioxidant only ethanol.

\section{Thiobarbituric Acid Reactive Substances (TBARS)}

The TBARS method of Buege and Aust [30] was used to monitor the oxidation and accumulation of the secondary lipid peroxidation products, such as aldehydes and related carbonyl compounds, in the commercial corn oil after heated for $0,1,2,4,6 \mathrm{~h}$. The TBAR reagent was prepared with equal volumes of $15 \% \mathrm{w} / \mathrm{v}$ TCA, $0.375 \% \mathrm{w} / \mathrm{v} 2$-thiobarbituric acid (TBA), and $0.25 \mathrm{~N}$ hydrochloric acid. Samples of $200 \mu \mathrm{L}$ of oil were combined with $4 \mathrm{~mL}$ of the reagent, and the mixture was heated for $15 \mathrm{~min}$ in boiling water. The absorbance of the sample was measured in triplicates at $535 \mathrm{~nm}$ with a UV/Vis spectrophotometer. The calibration curve was prepared with a pure malondialdehyde (MDA) standard, and the results were expressed as nmol MDA equivalents per $g$ oil.

\section{HPLC Analysis of HNE}

The method used as described in detail [21] [22] [25].

Brief description of the method:

1) The preparation of 2,4-dinitrophenylhydrazine (DNPH) reagent was made from $10 \mathrm{mg} \mathrm{DNPH}$, three times recrystallized from methanol. The recrystallized DNPH was mixed with $20 \mathrm{~mL} 1 \mathrm{~N} \mathrm{HCl}$ and heated at $50^{\circ} \mathrm{C}$ for $1 \mathrm{~h}$. After cooling it was extracted four times with HPLC-grade hexane to remove impurities. The DNPH reagent was used immediately.

2) Transesterification of aldehydes and related carbonyl compounds was carried out in duplicates by using $1 \mathrm{gr}$ of unheated or previously heated oil samples, and $5 \mathrm{~mL}$ of freshly prepared DNPH reagents, the samples were shaken overnight at room temperature in the dark.

3) The DNPH derivatives were extracted from the oil with $10 \mathrm{~mL}$ of methanol:water $(75: 25, \mathrm{v} / \mathrm{v})$ repeatedly three times.

4) From the combined methanol:water samples, the DNPH derivatives were extracted three times with $10 \mathrm{~mL}$ of dichloromethane. The combined dichloromethane extracts were concentrated under $\mathrm{N}_{2}$ gas to $0.5 \mathrm{~mL}$.

5) The DNPH derivatives, from the $0.5 \mathrm{~mL}$ dichloromethane extracts, were separated to polar and nonpolar compounds and osozones by thin-layer chromatography (TLC) using 2 silica gel plates per sample and developed in dichloromethane.

6) The polar compounds were individually eluted from the thin plates 3 times with $10 \mathrm{~mL}$ methanol. The combined methanol extracts, after centrifugation, to remove residual silica gel, were concentrated under $\mathrm{N}_{2}$ gas to $1 \mathrm{~mL}$. The concentrated polar DNPH derivatives were filtered by a syringe filter nylon membrane 
$0.45 \mu \mathrm{m}$ pore. Samples were stored in $-20^{\circ} \mathrm{C}$ until HPL analysis.

7) Aliquots of $100 \mu \mathrm{L}$ samples of the polar DNPH derivatives in duplicates were injected into the HPLC system. The integration of peaks was completed with a Varian Star Chromatography Workstation installed on a computer and connected to the detector. The DNPH derivatives were separated using isocratic elution with methanol-water $(50: 50, \mathrm{v} / \mathrm{v})$ for $10 \mathrm{~min}$, then a linear gradient to $100 \%$ methanol for $30 \mathrm{~min}$, after than maintaining $100 \%$ methanol for an additional $10 \mathrm{~min}$. The flow rate was $0.8 \mathrm{~mL} \mathrm{~min}^{-1}$ and the absorbance was monitored at $378 \mathrm{~nm}$. Since the retention time can change slightly, pure standard of HNE used as an external standard before each injection period. Identification of samples was by comparing the retention times of samples to the retention times of pure standard. For additional identification, co-chromatography was used. Known amount of sample was mixed with known amount of the pure standard. The recovery was calculated from the increased peak area due to the added standard. Recovery rates were between $95 \%$ and $105 \%$. The detection limit of samples was $1 \mathrm{ng}$. Since every duplicate sample was analyzed separately and injected in duplicates for HPLC analysis, the minimum numbers of the HPLC chromatograms were 4 for each sample analyzed.

\section{Fatty Acid Distribution}

The fatty acid distribution of the unheated corn oil was measured by gas chromatography using the method of Metcalf and Schmitz [31]. The fatty acid distribution was measured comparing the fatty acid methyl esters retention times of the samples to the standards [32]. The results are expressed as \% of total fatty acids.

\section{Peroxide Value Determination}

The peroxide value (PV) in unheated commercial corn oil was measured in duplicates by the Official Methods of the American Oil Chemists' Society. Four identical samples were used with triplicate titrations to determine the PV.

\section{Statistical Analysis}

Analysis of variance was used to determine the significant differences between groups. All measurements were replicated three times. The results obtained were statistically analyzed with two-way ANOVA. The Tukey test was conducted to calculate $\mathrm{P}$ values. Significant differences were determined at $\mathrm{P} \leq 0.05$.

\section{Results and Discussion}

The main objective of the present experiments was to measure the heat-induced secondary lipid peroxidation, with special reference to the formations of the toxic 4-hydroxynonenal (HNE) in the presence and absence of certain antioxidants.

Before the major objective, to measure the formation of HNE, preliminary experiments were conducted including the TBARS assay to measure the formation of all aldehydes and related carbonyl compounds at $185^{\circ} \mathrm{C}$ frying temperature, up to 6 hours, in the presence and absence of certain antioxidants [33]. 
Results of the TBARS assay were also used to determine the conditions to be used for the much longer HPLC based measurements of HNE retardation by antioxidants in the heat-treated corn oil samples at $185^{\circ} \mathrm{C}$, up to 6 hours duration.

\section{Peroxide Value (PV)}

Four identical commercial corn oil samples were used to measure the PV before the oil was heat-treated. The results showed that PV was 1.70 - 1.76 milliequivalents $/ 1000 \mathrm{~g}$ corn oil. This indicates that the corn oil used was minimally oxidized before the beginning of thermal treatments.

\section{Fatty Acid Distribution}

The commercial corn oil used in the following experiments contained $43.7 \%$ linoleic acid, $34.2 \%$ oleic acid, 19.3\% palmitic acid and $2.8 \%$ stearic acid. It did not contain linolenic acid and arachidonic acid. Linoleic acid, which contains 2 double bonds, is a precursor for HNE, and oleic acid which contains only one double bond was shown not to be a precursor for HNE [20].

Thiobarbituric Acid Reactive Substances (TBARS)

Duplicate corn oil samples were heated individually for each time period of 0 , $1,2,3,4$ and 6 hours at $185^{\circ} \mathrm{C}$. Results of the TBARS assay showed the highest level of secondary lipid oxidation product formations in corn oil without added antioxidants after 6 hours of thermal treatment at $185^{\circ} \mathrm{C}$. The formation of TBARS in the absence and the presence of various antioxidants are presented in detail in figures between Figures 1(a)-3(b). The TBARS concentrations were expressed as malondialdehyde (MDA) equivalents per $\mu \mathrm{g} / \mathrm{mL}$ of oil.

Figure 1(a) and Figure 1(B) show no measurable antioxidant activity in the presence of 100, 200 and 300 ppm TBHQ or 100 and 200 ppm AP alone. The middle concentration TBHQ $200 \mathrm{ppm}$ was selected in the following measurements and mixed with other antioxidants or synergists. Figure 2(a) also shows no antioxidant effects for the mixture of TBHQ 200 ppm + AP 100 ppm or 200 ppm. Figure 2(b) also shows no antioxidants effects for the mixture of TBHQ $200 \mathrm{ppm}+$ CA $50 \mathrm{ppm}$ or $100 \mathrm{ppm}$.

Figure 3(a) shows that the mixture of TBHQ $200 \mathrm{ppm}+\mathrm{AP} 100 \mathrm{ppm}+\mathrm{Ca} 50$ ppm, can significantly lower the oxidation, at frying temperature, the 6 hour heat treated corn oil. A previous study reported that AP has antioxidant activity [34]. It was also reported that AP retarded the oxidation in oil at frying temperature [35]. However, in the present study, AP alone had no lowering effects of TBARS formation of heat-treated corn oil.

Figure 3(b) shows the antioxidant activity of 50, 100 and 200 ppm of RE. Results show that as low of $50 \mathrm{ppm}$ RE in the oil reduced statistically the TBARS formation at frying temperature already after 2 hours of heating time.

Present results indicate that AP and CA, secondary antioxidants, act as synergists with the primary antioxidant TBHQ and retard the oxidation of corn oil at frying temperature measured by the TBARS assay.

In summary, it was found that the maximum suppression of lipid oxidation 

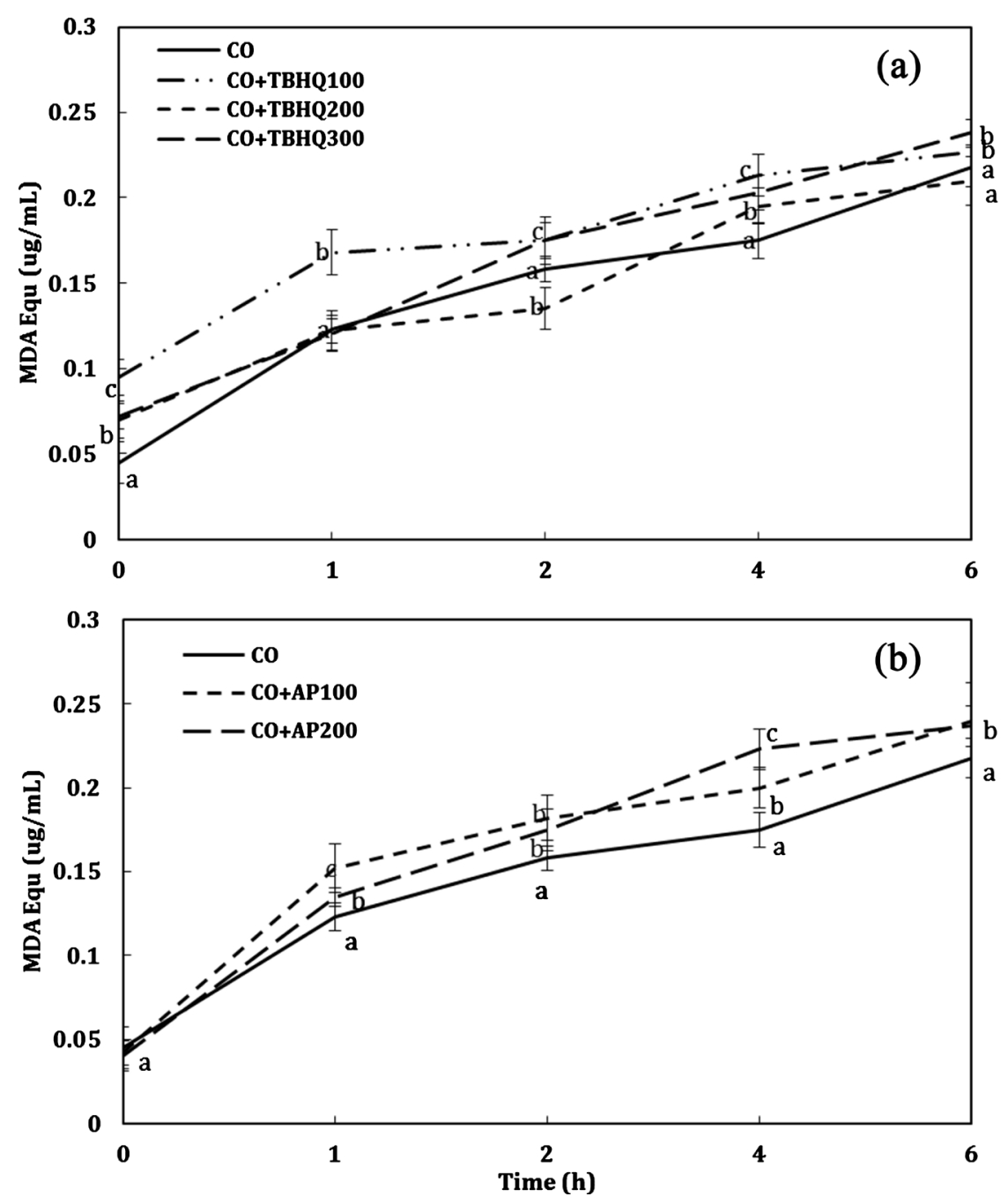

Figure 1. (a) Comparison of TBARS expressed as MDA equivalents of heat-treated corn oil for $0,1,2,4$ and 6 hours at $185^{\circ} \mathrm{C}$ in the presence and absence of $100 \mathrm{ppm}, 200 \mathrm{ppm}$ and $300 \mathrm{ppm}$ TBHQ. (b) Comparison of TBARS expressed as MDA equivalents of heat-treated corn oil for $0,1,2,4$ and 6 hours at $185^{\circ} \mathrm{C}$ in the presence and absence of 100 ppm and 200 ppm ascorbyl palmitate (AP).

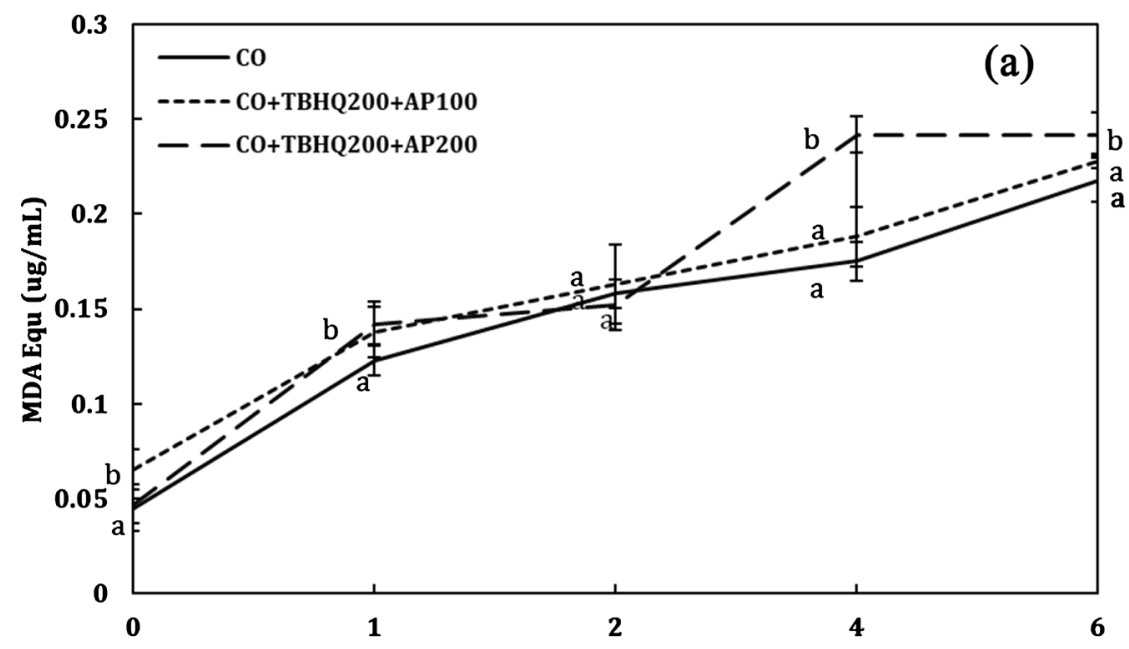




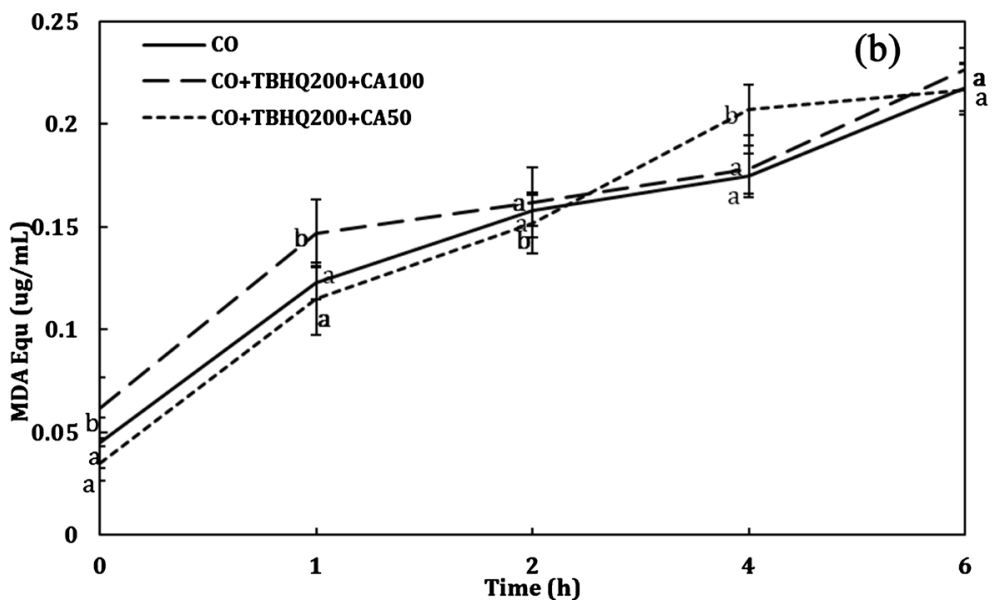

Figure 2. (a) Comparison of TBARS expressed as MDA equivalents of heat-treated corn oil for $0,1,2,4$ and 6 hours at $185^{\circ} \mathrm{C}$ in the presence and absence of $200 \mathrm{ppm}$ TBHQ and $100 \mathrm{ppm}$ or $200 \mathrm{ppm}$ ascorbyl palmitate (AP). (b) Comparison of TBARS expressed as MDA equivalents of heat-treated corn oil for $0,1,2,4$ and 6 hours at $185^{\circ} \mathrm{C}$ in the presence and absence of $200 \mathrm{ppm}$ TBHQ and $50 \mathrm{ppm}$ or $100 \mathrm{ppm}$ citric acid (CA).
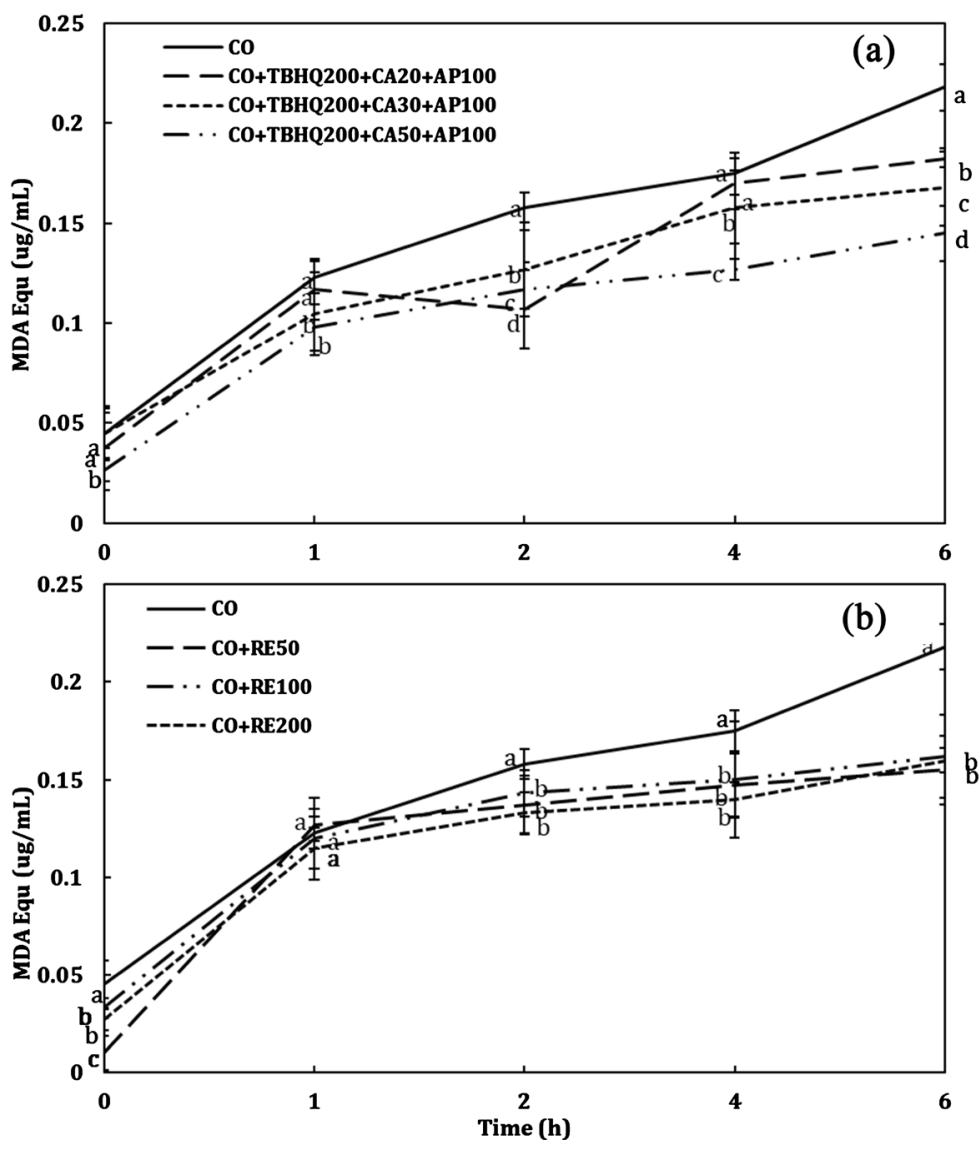

Figure 3. (a) Comparison of TBARS expressed as MDA equivalents of heat-treated corn oil for $0,1,2,4$ and 6 hours at $185^{\circ} \mathrm{C}$ in the presence and absence of a mixture of $200 \mathrm{ppm}$ TBHQ, $100 \mathrm{ppm}$ ascorbyl palmitate (AP) and $20 \mathrm{ppm}$ or $30 \mathrm{ppm}$ or $50 \mathrm{ppm}$ citric acid (CA). (b) Comparison of TBARS expressed as MDA equivalents of heat-treated corn oil for $0,1,2,4$ and 6 hours at $185^{\circ} \mathrm{C}$ in the presence and absence of $50 \mathrm{ppm}, 100 \mathrm{ppm}$ or 200 ppm rosemary extracts $(\mathrm{RE})$. 
measured by the TBARS assay, in corn oil heated for 6 hours at $185^{\circ} \mathrm{C}$, was $33 \%$ by the mixture of $200 \mathrm{ppm}$ TBHQ $+50 \mathrm{ppm}$ citric acid (CA) + $100 \mathrm{ppm}$ ascorbyl palmitate (AP). The suppression of oxidation by rosemary extracts (RE) 50 or $100 \mathrm{ppm}$ was $29 \%$ for heat-treated corn oil. Several studies have recommended the use of rosemary extracts as an alternative antioxidant to synthetic antioxidants [36] [37]. The compounds responsible for rosemary extracts' antioxidant properties are mainly phenolic diterpenes, such as carnosol, carnosic acid, rosmanol, epirosmanol and isorosmanol [28].

The deterioration of frying fats and oils at high temperatures is complicated, because oxidative and thermolytic reactions are occurring simultaneously, and both the saturated and unsaturated fatty acids undergo chemical degradations when exposed to high temperatures and oxygen [38] resulting in the formation of aldehydes, ketones and related carbonyl compounds.

After the suppression of oxidation of heat-treated corn oil was established by the mixture of synthetic and one natural antioxidant by the measurements of TBARS, the main objective was to measure the suppressing effects of these antioxidants on the formation of the toxic $\alpha, \beta$-unsaturated-4-hydroxyaldehyde HNE, in heat-treated corn oil at frying temperature $\left(185^{\circ} \mathrm{C}\right)$ up to 6 hours.

Figure 4(a) illustrates the formation of $\mathrm{HNE}$ in corn oil heated at $185^{\circ} \mathrm{C}$ for 0 , $1,2,4$ and 6 hours in the absence and the presence of synthetic antioxidants and their mixtures. These are $200 \mathrm{ppm}$ TBHQ alone, $200 \mathrm{ppm}$ TBHQ + $50 \mathrm{ppm} \mathrm{CA}$, $200 \mathrm{ppm}$ TBHQ $+100 \mathrm{ppm} \mathrm{AP}$ and $200 \mathrm{ppm}$ TBHQ $+50 \mathrm{ppm} \mathrm{CA}+100 \mathrm{ppm}$ AP. Results show that after 2, 4 and 6 hours of heat treatment at $185^{\circ} \mathrm{C}$, the HNE concentration was significantly suppressed by $27 \%$ in the corn oil by both mixtures of $200 \mathrm{ppm}$ TBHQ $+50 \mathrm{ppm} \mathrm{CA}$ and $200 \mathrm{ppm}$ TBHQ + $50 \mathrm{ppm} \mathrm{CA}+100$ ppm AP. While the synergistic effect of AP and CA was evident in measuring the TBARS reaction in heated corn oil, for the HNE formation of AP was not significant. While the TBARS are measuring all the various secondary oxidation products including the polar and nonpolar aldehydes and related carbonyl compounds, HNE is only a 9 carbon $\alpha, \beta$-unsaturated-4-hydroxyaldehyde. It seems that the synergistic effect of AP with TBHQ, a primary antioxidant, is not affecting the formation of HNE.

Figure 4(b) shows the retardation of $\mathrm{HNE}$, in corn oil heated at $185^{\circ} \mathrm{C}$ up to 6 hours in the absence and presence of $50 \mathrm{ppm}$ or $100 \mathrm{ppm} \mathrm{RE}$ and it was retarded by $29 \%$. Significant suppression of HNE formation due to both $50 \mathrm{ppm}$ or 100 ppm RE can be seen after 4 and 6 hours of heat treatment of the corn oil.

In summary, the results of Figure 4(a) and Figure 4(b) show the best combination of synthetic antioxidants used in this study, to suppress the formation of HNE after 6 hours of thermal treatment at $185^{\circ} \mathrm{C}$. This was $200 \mathrm{ppm}$ TBHQ +50 ppm CA + 100 ppm AP. Results of RE of 50 or 100 ppm under the same conditions, similarly reduced the HNE formation.

Previously, investigators have reported the protective effect of polymethylsiloxane (PDMS) in the formation of HNE in soybean oil at frying temperature. 
However, the protective effect was not due to antioxidants, but the protection was due to the prevention of oxygen penetration into the monolayer of the oil surface, therefore lowering the oxidation of the oil and lowering the decomposition of linoleate and the formation of HNE [39].

Figure 5(a) illustrates the sum total of polar aldehydes (PA) and related carbonyl compounds (RCC) formations in corn oil heat-treated at $185^{\circ} \mathrm{C}$ for $0,1,2$, 4 and 6 hours in the absence and presence of synthetic antioxidants and their mixtures measured by HPLC. Results show that PA and RCC concentrations were very low at 0 time. After 6 hours of thermal treatment, the combination of $200 \mathrm{ppm}$ TBHA $+50 \mathrm{ppm} \mathrm{CA}+100$ ppm AP suppressed the formation of the sum total of polar aldehydes by $72 \%$ as expressed as hexanal equivalents.

Figure 5(b) shows the effect of RE on the sum total of polar aldehydes (PA) and
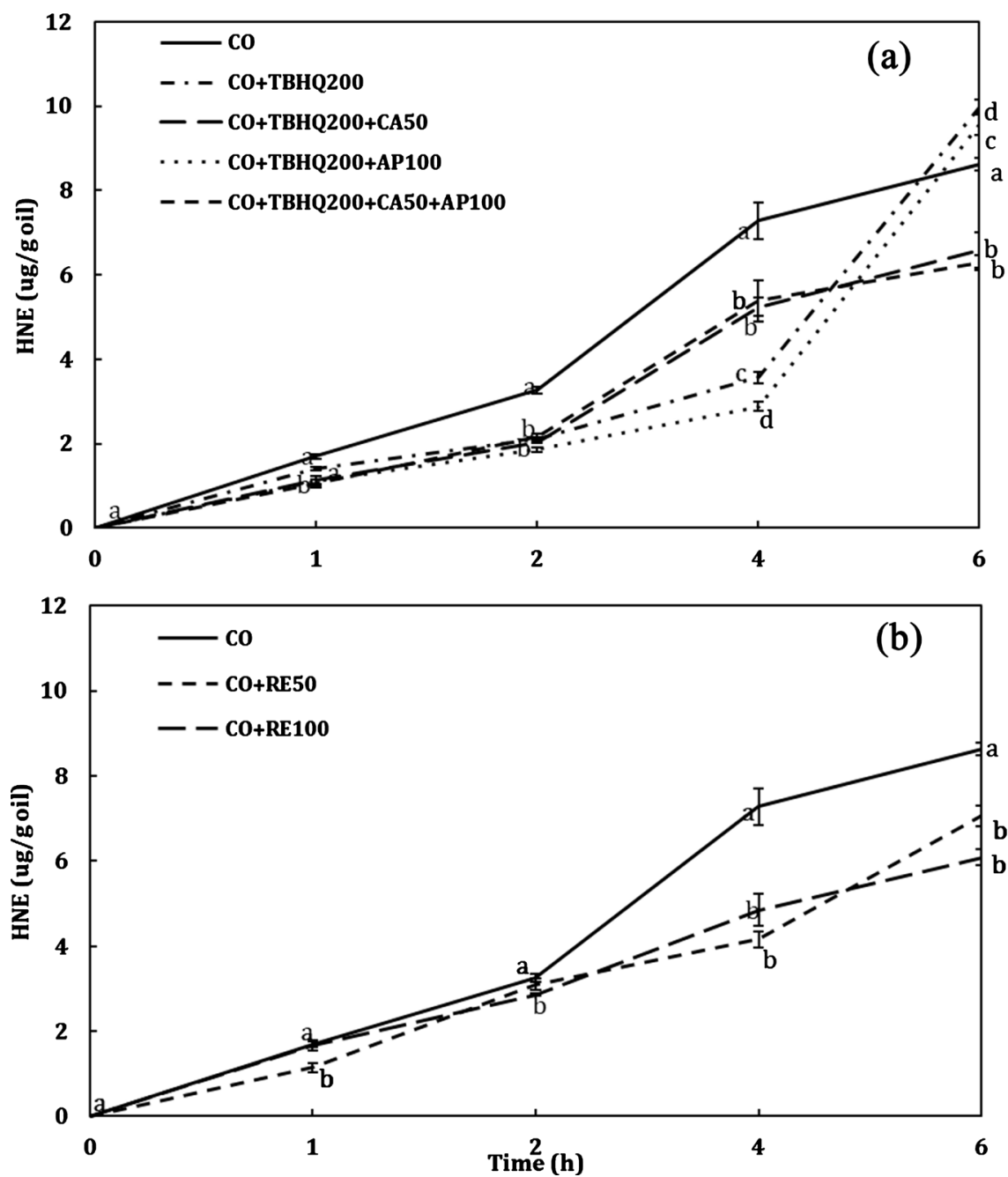

Figure 4. (a) Formation of HNE in corn oil heat-treated at $185^{\circ} \mathrm{C}$ for $0,1,2,4$ and 6 hours in the presence and absence of synthetic antioxidants and their mixtures. $200 \mathrm{ppm}$ TBHQ, 200 ppm TBHQ and 50 ppm CA, 200 ppm TBHQ and 100 ppm AP, 200 ppm TBHQ and $50 \mathrm{ppm} \mathrm{CA}$ and $100 \mathrm{ppm}$ AP. (b) Formation of HNE in corn oil heat-treated at $185^{\circ} \mathrm{C}$ for $0,1,2,4$ and 6 hours in the presence and absence of $50 \mathrm{ppm}$ and $100 \mathrm{ppm}$ rosemary extracts (RE). 

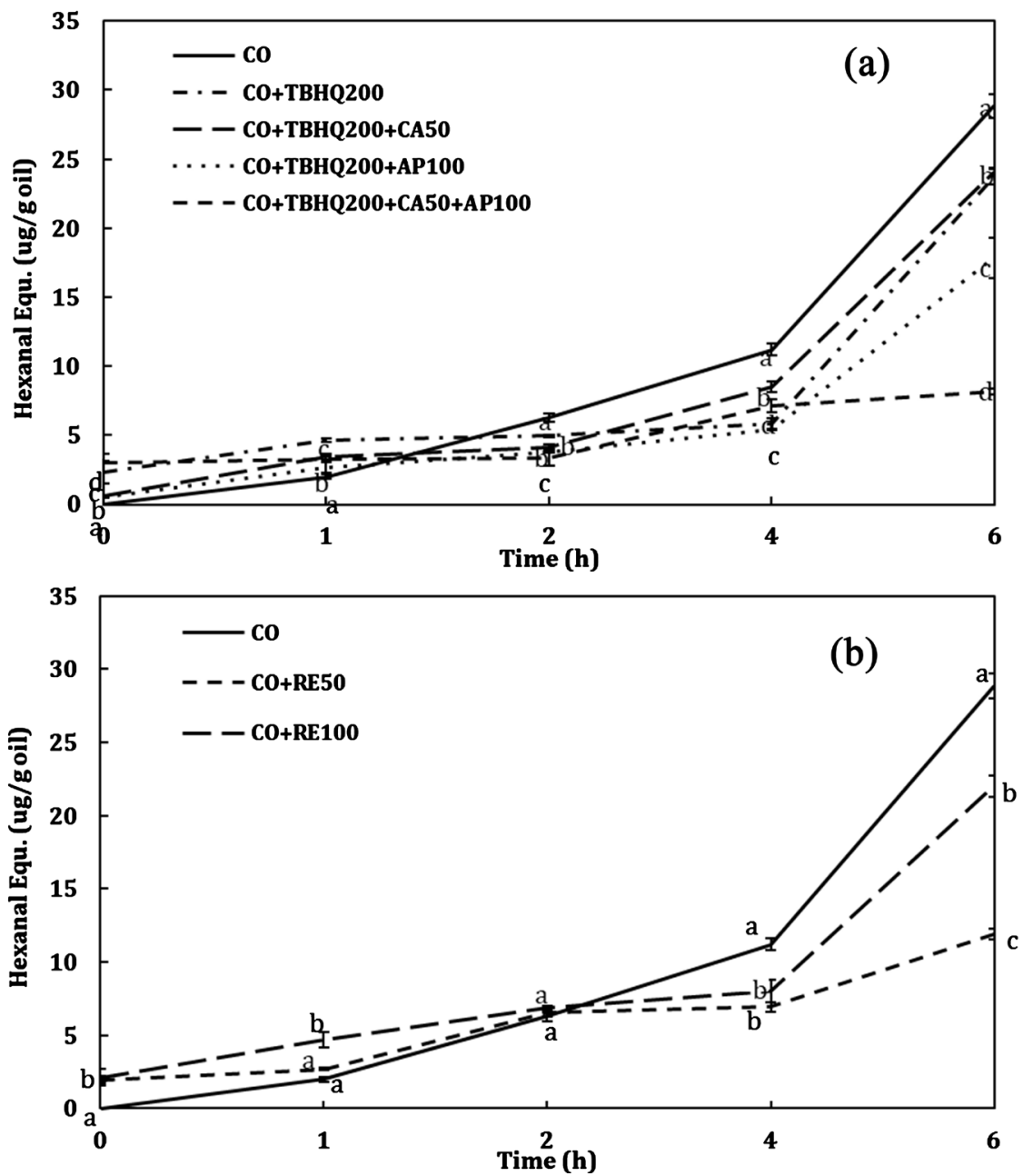

Figure 5. (a) The sum total of polar aldehydes and related carbonyl compounds in corn oil heat-treated at $185^{\circ} \mathrm{C}$ for $0,1,2,4$ and 6 hours in the presence and absence of synthetic antioxidants and their mixtures. $200 \mathrm{ppm}$ TBHQ, $200 \mathrm{ppm}$ TBHQ and $50 \mathrm{ppm} \mathrm{CA}, 200$ ppm TBHQ and 100 ppm AP, 200 ppm TBHQ and 50 ppm CA and 100 ppm AP. Expressed as hexanal equivalents/g oil. (b) The sum total of polar aldehydes and related carbonyl compounds in corn oil heat-treated at $185^{\circ} \mathrm{C}$ for $0,1,2,4$ and 6 hours in the presence and absence of $50 \mathrm{ppm}$ and $100 \mathrm{ppm}$ rosemary extracts (RE). Expressed as hexanal equivalents/g oil.

related carbonyl compounds (RCC) formation measured by HPLC in corn oil in the presence of up to 6 hours of heat treatments in $185^{\circ} \mathrm{C}$. After 4 hours of heat treatment, both 50 and 100 ppm REs are significantly lowered by the formation of PA and RCC. However, after 6 hours of heat treatment, 50 ppm RE was found to be the most effective. It suppressed 59\% of the sum total formations of PA and RCC expressed as hexanal equivalents.

When the antioxidant effects of the natural and synthetic antioxidants were measured by the TBARS assay, the mixture of TBHQ $200 \mathrm{ppm}+\mathrm{CA} 50 \mathrm{ppm}+$ AP $100 \mathrm{ppm}$ demonstrated 33\% lower total lipid oxidation and as low as $50 \mathrm{ppm}$ RE demonstrated $29 \%$ lower lipid oxidation compared to the untreated corn oil due to thermal treatment for 6 hours at $185^{\circ} \mathrm{C}$. It should be mentioned that corn 
oil contains high concentration of linoleic acid, a precursor for HNE. The formation of HNE, a toxic aldehyde, form from $\omega-6$ fatty acids which have been reported and confirmed in the literature [20] [40] [41].

In summary, the greatest reduction of HNE formation (29\%) after 6 hours of heat treatment at $185^{\circ} \mathrm{C}$ was produced by the addition of $100 \mathrm{ppm}$ RE. This was followed by the suppression of $27 \%$ HNE by the combination of $200 \mathrm{ppm}$ TBHQ $+100 \mathrm{ppm} \mathrm{AP}+50 \mathrm{ppm} \mathrm{CA}$.

In conclusion, the present experiments demonstrated that certain synthetic antioxidant mixtures and a naturally occurring antioxidant at certain low concentrations will retard the overall lipid peroxidation process of heat-treated commercial corn oil at of $185^{\circ} \mathrm{C}$ up to 6 hours as measured by the TBARS assay and also reduce the formation of the most toxic $\alpha, \beta$-unsaturated hydroxyaldehyde HNE, measured by HPLC.

\section{Conflicts of Interest}

The authors declare no conflicts of interest regarding the publication of this paper.

\section{References}

[1] Kim, S.-S., Gallaher, D.D. and Csallany, A.S. (1999) Lipophilic Aldehydes and Related Carbonyl Compounds in Rat and Human Urine. Lipids, 34, 489-496. https://doi.org/10.1007/s11745-999-0389-1

[2] Grootveld, M., Ahterton, M.D., Sheerin, A.N., Hawkes, J., Blake, D.R., Richens, T.E., Silwood, C.J., Lynch, E. and Claxson, A.W. (1998) In Vivo Absorption, Metabolism, and Urinary Excretion of $\alpha, \beta$-Unsaturated Aldehydes in Experimental Animals. The Journal of Clinical Investigation, 101, 1210-1218. https://doi.org/10.1172/JCI1314

[3] Kanazawa, K., Kanazawa, E. and Natake, M. (1985) Uptake of Secondary Autoxidation Products of Linoleic Acid by the Rat. Lipids, 20, 412-419. https://doi.org/10.1007/BF02534231

[4] Witz, G. (1989) Biological Interactions of $\alpha, \beta$-Unsaturated Aldehydes. Free Radical Biology and Medicine, 7, 333-349. https://doi.org/10.1016/0891-5849(89)90137-8

[5] Comporti, M. (1993) Lipid Peroxidation. Biopathological Significance. Molecular Aspects of Medicine, 14, 199-207. https://doi.org/10.1016/0098-2997(93)90006-Y

[6] Kanazawa, K. and Ashida, H. (1991) Target Enzymes on Hepatic Dysfunction Caused by Dietary Products of Lipid Peroxidation. Archives of Biochemistry and Biophysics, 288, 71-78. https://doi.org/10.1016/0003-9861(91)90166-G

[7] Kaneko, T., Kaji, K. and Matsuo, M. (1988) Cytotoxicities of a Linoleic Acid Hydroperoxide and Its Related Aliphatic Aldehydes toward Cultured Human Umbilical Vein Endothelial Cells. Chemico-Biological Interactions, 67, 295-304. https://doi.org/10.1016/0009-2797(88)90065-8

[8] Schauenstein, E. and Esterbauer, H. (1977) Aldehydes in Biological Systems, Their Natural Occurrence and Biological Activities. Pion Ltd., London, 35-38.

[9] Esterbauer, H., Gebicki, J., Puhl, H. and Jurgens, G. (1992) The Role of Lipid Peroxidation and Antioxidants in Oxidative Modification of LDL. Free Radical Biology and Medicine, 13, 341-390. https://doi.org/10.1016/0891-5849(92)90181-F 
[10] Uchida, K., Osawa, T., Hiai, H. and Toyokuni, S. (1995) 4-Hydroxy-2-NonenalTrapping ELISA: Direct Evidence for the Release of a Cytotoxic Aldehyde from Oxidized Low Density Lipoproteins. Biochemical and Biophysical Research Communications, 212, 1068-1073. https://doi.org/10.1006/bbrc.1995.2078

[11] Palinski, W., Rosenfeld, M.E., Yla-Herttuala, S., Gurtner, G.C., Socher, S.S., Butler, S.W., Parthasarathy, S., Carew, T.E., Steinberg, D. and Witztum, J.L. (1989) Low Density Lipoprotein Undergoes Oxidative Modification in Vivo. Proceedings of the National Academy of Sciences of the United States of America, 86, 1372-1376. https://doi.org/10.1073/pnas.86.4.1372

[12] Hoff, N.F., O’Neil, J., Chisolm 3rd, G.M., Cole, T.B., Quehenberger, O., Esterbauer, H. and Jürgens, G. (1989) Modification of Low Density Lipoprotein with 4-Hydroxynonenal Induces Uptake by Macrophages. Arteriosclerosis, 9, 538-549. https://doi.org/10.1161/01.ATV.9.4.538

[13] Schaur, R.J. (2003) Basic Aspects of the Biochemical Reactivity of 4-Hydroxynonenal. Molecular Aspects of Medicine, 24, 149-159. https://doi.org/10.1016/S0098-2997(03)00009-8

[14] Leonarduzzi, G., Chiarpotto, E., Biasi, F. and Poli, G. (2005) 4-Hydroxynonenal and Cholesterol Oxidation Products in Atherosclerosis. Molecular Nutrition \& Food Research, 49, 1044-1049. https://doi.org/10.1002/mnfr.200500090

[15] Parola, M., Pinzani, M., Casini, A., Albano, E., Poli, G., Gentilini, A., Gentilini, P. and Dianzani, M.U. (1993) Stimulation of Lipid Peroxidation or 4-Hydroxynonenal Treatment Increases Procollagen $\alpha 1$ (I) Gene Expression in Human Liver Fat-Storing Cells. Biochemical and Biophysical Research Communications, 194, 1044-1050. https://doi.org/10.1006/bbrc.1993.1927

[16] Tsuneyama, K., Harada, K., Kono, N., Sasaki, M., Saito, T., Gershwin, M.E., Ikemoto, M., Arai, H. and Nakanuma, Y. (2002) Damaged Interlobular Bile Ducts in Primary Biliary Cirrhosis Show Reduced Expression of Glutathione-S-Transferase-Pi and Aberrant Expression of 4-Hydroxynonenal. Journal of Hepatology, 37, 176-183. https://doi.org/10.1016/S0168-8278(02)00105-8

[17] Castellani, R.J., Perry, G., Siedlak, S.L., Nunomura, A., Shimohama, S., Zhang, J., Montine, T., Sayre, L.M. and Smith, M.A. (2002) Hydroxynonenal Adducts Indicate a Role for Lipid Peroxidation in Neocortical and Brainstem Lewy Bodies in $\mathrm{Hu}$ mans. Neuroscience Letters, 319, 25-28.

https://doi.org/10.1016/S0304-3940(01)02514-9

[18] Mark, R.J., Lovell, M.A., Markesbery, W.R., Uchida, K. and Mattson, M.P. (1997) A Role for 4-Hydroxynonenal, an Aldehydic Product of Lipid Peroxidation, in Disruption of Ion Homeostasis and Neuronal Death Induced by Amyloid $\beta$-Peptide. Journal of Neurochemistry, 68, 255-264. https://doi.org/10.1046/j.1471-4159.1997.68010255.x

[19] Goicoechea, E., Brandon, E.F.A., Blokland, M.H. and Guillén, M.D. (2011) Fate in Digestion in Vitro of Several Food Components, Including Some Toxic Compounds Coming from Omega-3 and Omega-6 Lipids. Food and Chemical Toxicology, 49, 115-124. https://doi.org/10.1016/j.fct.2010.10.005

[20] Han, I.H. and Csallany, A.S. (2009) Formation of Toxic $\alpha, \beta$-Unsaturated 4-Hydroxyaldehydes in Thermally Oxidized Fatty Acid Methyl Esters. Journal of the American Oil Chemists' Society, 86, 253-260.https://doi.org/10.1007/s11746-008-1343-6

[21] Seppanen, C.M. and Csallany, A.S. (2001) Simultaneous Determination of Lipophilic Aldehydes by High Performance Liquid Chromatography in Vegetable Oil. Journal of the American Oil Chemists' Society, 78, 1253-1260. https://doi.org/10.1007/s11745-001-0422-9 
[22] Seppanen, C.M. and Csallany, A.S. (2002) Formation of 4-Hydroxynonenal, a Toxic Aldehyde in Soybean Oil at Frying Temperature. Journal of the American Oil Chemists' Society, 79, 1033-1038. https://doi.org/10.1007/s11746-002-0598-z

[23] Seppanen, C.M. and Csallany, A.S. (2006) The Effect of Intermittent and Continuous Heating of Soybean Oil at Frying Temperature on the Formation of HNE and Other $\alpha$-, $\beta$-Unsaturated Hydroxyaldehydes. Journal of the American Oil Chemists Society, 83, 121-127. https://doi.org/10.1007/s11746-006-1184-0

[24] Han, I.H. and Csallany, A.S. (2008) Temperature Dependence of HNE Formation in Vegetable Oils and Butter Oil. Journal of the American Oil Chemists' Society, 85, 777-782. https://doi.org/10.1007/s11746-008-1250-X

[25] Yuan, J.Y., Shoeman, D. W. and Csallany, A.S. (2018) Formation of 4-Hydroxy-2Transnonenal, a Toxic Aldehyde in Thermally Treated Olive and Sunflower Oils. Journal of the American Oil Chemists' Society, 95, 813-823. https://doi.org/10.1002/aocs.12098

[26] Seppanen, C.M. and Csallany, A.S. (2004) Incorporation of the Toxic Aldehyde 4-Hydroxy-2-trans-Nonenal into Food Fried in Thermally Oxidized Soybean Oil. Journal of the American Oil Chemists' Society, 81, 1137-1141. https://doi.org/10.1007/s11746-004-1031-3

[27] Csallany, A.S., Han, I., Shoeman, D.W., Chen, C. and Yuan, J.Y. (2015) 4-Hydroxynonenal (HNE), a Toxic Aldehyde in French Fries from Fast Food Restaurants. Journal of the American Oil Chemists' Society, 92, 1413-1419. https://doi.org/10.1007/s11746-015-2699-z

[28] Schwarz, K. and Ternes, W. (1992) Anioxidative Constituents of Rosmarinus officialis and Salvia offcialis. Isolation of Carnosic Acid and other Phenolic Diterpenes. Zeitschrift fur Labensmittel Untersuchung und Forschung, 195, 99-103. https://doi.org/10.1007/BF01201766

[29] Erkan, N., Ayranci, G. and Ayranci, E. (2008) Antioxidant Activities of Rosemary (Rosmarius officialis L.) Extract, Blackseed (Nigella sativa L.), Essential Oil, Carnosic Acid, Rosmarinic Acid and Sesamol. Food Chemistry, 110, 76-82. https://doi.org/10.1016/j.foodchem.2008.01.058

[30] Burge, J.A. and Aust, S.D. (1978) Micosomal Lipid Peroxidation. Methods of Enzymology, 52, 302-310. https://doi.org/10.1016/S0076-6879(78)52032-6

[31] Metcalf, L.D. and Smitz, A.A. (1961) The Rapid Preparation of Fatty Acid Esters for Gas Chromatographic Analysis. Analytical Chemistry, 33, 363-364.

https://doi.org/10.1021/ac60171a016

[32] (1997) Official Methods of the American Oil Chemist's Society.

[33] Liu, X.Y., Shoeman, D.W., Yuan, J.Y. and Csallany, A. S. (2018) Effects of Temperature and Heating Time on the Formation of Four Toxic $\alpha, \beta$-Unsaturated-4-Hydroxyaldehydes in Vegetable Oils. Journal of the American Oil Chemists Society, 95, 607-617. https://doi.org/10.1002/aocs.12067

[34] Cort, W.M. (1974) Antioxidant Activity of Tocopherols, Ascorbyl Palmitate and Ascorbic Acid and Their Mode of Action. Journal of the American Oil Chemists Society, 51, 321-325. https://doi.org/10.1007/BF02633006

[35] Gwo, Y.-Y., Flick, G.J., Dupay, H.P., Ory, R.L. and Baran, W.L. (1985) Effect of Ascorbyl Palmitate on the Quality of Frying Fats for Deep Frying Operations. Journal of the American Oil Chemists' Society, 62, 1666-1671. https://doi.org/10.1007/BF02541662

[36] Merril, L.D., Pike, O.A., Ogden, L.V. and Dunn, M.L. (2008) Oxidative Stability of 
Conventional and High-Oleic Vegetable Oils with Added Antioxidants. Journal of the American Oil Chemists' Society, 85, 771-776.

https://doi.org/10.1007/s11746-008-1256-4

[37] Gamez-Meza, N., Noriega-Rodriguez, J.A., Leyva-Carrillo, L., Ortega-Garcia, J., Bringas-Alvarado, L., Garcia, H.S. and Medina-Juarez, L.A. (2009) Antioxidant Activity Comparison of Thompson Grape Pomace Extract, Rosemary and Tocopherols in Soybean Oil. Journal of Food Processing Preservation, 33, 110-120. https://doi.org/10.1111/j.1745-4549.2008.00285.x

[38] Simic, M.G. and Karel, M., Eds. (1980) Autoxidation in Food and Biological Systems. Plenum Press, New York.

[39] Garde, J.A., Hammond, E.G. and White, P.J. (2011) Influence of Polydimethylsiloxane on the Formation of 4-Hydroxynonenal in Soybean Oil at Frying Temperature. Journal of the American Oil Chemists' Society, 88, 1503-1510. https://doi.org/10.1007/s11746-011-1811-2

[40] Esterbauer, H. (1982) Aldehydic Products of Lipid Peroxidation. In: Mcbrien, D.G.H. and Slater, T.F., Eds., Free Radicals Lipid Peroxidation and Cancer, Academic Press, Cambridge, 101-128.

[41] Poli, G., Dinzani, M.U., Cheeseman, K.H., Slater, T.F., Lang, J. and Esterbauer, H. (1985) Separation and Characterization of the Aldehydic Products of Lipid Peroxidation Stimulated by Carbon Tetrachloride or ADP-Iron in Isolated Rat Hepatocytes and Rat Liver Microsomal Suspensions. Biochemical Journal, 227, 629-638. https://doi.org/10.1042/bj2270629 